\title{
AOR
}

Selected Papers of \#AoIR2021:

The 22nd Annual Conference of the

Association of Internet Researchers

Virtual Event / 13-16 Oct 2021

\section{HANDMADE HUSTLE: ETSY, WHITENESS, AND GENDERED PRECARITY}

Jacqueline Johnson

University of Southern California

\section{Introduction}

In their book Starting an Etsy Business for Dummies, Allison Strine and Kate Shoup (2011) outline strategies for aspiring Etsy sellers to "channel their passion for their craft into their life's work" (p. 1). Strine and Shoups's book isn't the only guide for Etsy sellers; there are multiple books, blog posts, and even a course at UT Austin dedicated to this topic. These how-to guides, and the platform itself, position Etsy as a site to leverage the skills associated with domestic femininities into capital and community. Additionally, they romanticize working as a seller on Etsy by framing it as a type of liberatory independence: independence from bosses, from scheduling, from the demands of office culture. This project is interested in questions about gender, race, labor, and platforms and seeks to examine how Etsy articulates new formations of raced and gendered labor directly tied to The Great Recession.

Scholars have analyzed Etsy's relationship to historic craft movements (Krugh 2014; Luckman 2013) and to fan handicrafting (Cherry 2016); however, there is still relatively little published research on Etsy. Adding to this growing body of scholarship, I foreground the ways in which whiteness and gender are co-constitutive on the platform. I situate Etsy within the literature on postfeminism and media culture (Gill 2007; McRobbie 2004), gender and passionate work (Duffy 2016; Duffy 2017; McRobbie 2018), and race and digital hustle economies (McMillan Cottom 2020). I analyze products sold on Etsy that rhetorically engage gendered labor dynamics and precarity through the language of hustling or entrepreneurship.

While the organizing logics of postfeminism and neoliberalism underpin the platform, I position Etsy and the products I examine as examples of what Diane Negra and Yvonne Tasker (2014) term "recessionary popular culture" (p. 6). In line with, but also distinct from postfeminist media culture, these "recessionary images of female resourcefulness have proliferated in forms that seek to retain traditionalist femininity under conditions of financial exigency" (p. 7). Etsy produces and circulates discourses about hustling and 
entrepreneurship that offer a distinctly racialized and gendered response to enhanced precarity centering middle-class, white femininities.

\section{Methods}

This project utilizes a cultural studies framing and relies on critical discourse and textual analysis. I use these methodologies to examine how the language printed on products, which include mostly screen-printed shirts, mugs, and wall art, promotes individual solutions to economic insecurity (see Figure 1 and 2). Additionally, I assess the following factors: product description, use of models, photo staging, color, and text fonts to make sense of how these products signal a particular raced and gendered subject.

Etsy allows users to select their region, language, and currency, and I elected to use the platform in English as someone in The U.S. with the U.S. dollar. Using Etsy's native search function, I searched for products containing the word "hustle" and its variations "hustler" and "hustling," as well as products that gender being a boss including "girl boss," "boss lady," "boss bitch," and "boss babe." Each of these terms yielded between 30,000 and 40,000 results with the exception of "girl boss" (greater than 65,000) and "boss bitch" (between 3,000 and 4,000). Due to the high volume of results, I looked at the first three pages each search term yielded and categorized the results by common threads.

\section{Findings}

I focus on three main threads I found in my analysis: 1) White women on the platform have co-opted Black vernacular to address how economic insecurity has pushed previously economically stable groups into gig labor 2 ) These products romanticize precarity by positioning feminized grit and individualized solutions to macro economic hurdles as female empowerment 3) The products discursively frame entrepreneurship as aspirational, liberatory, and, most centrally, compatible with white, domestic femininities.

Hustling has always had particular classed and raced connotations. However, The effects of neoliberal economic and social policy have pushed previously economically stable groups of Americans, like middle-class, white women, into gig labor and side hustles. The products I analyze demonstrate that Etsy is changing the image of the hustler. Many of these products moved hustling away from engagements in the informal economy (e.g. "Real Estate is my Hustle" "Mother Hustler"). Further, through the use of models, color, product staging, and what Vox calls "bridesmaid font" (Brooke, 2018), these products positioned the hustler as a white woman. Lastly, these products framed hustling as a mindset, where those with enough grit could make their own success (e.g "Stay Humble Hustle Hard" "Hustle Hard Pray Harder").

Similarly, products that gender being a boss illustrate an aspirational ethos that contends that an empowered woman is one who is her own boss. This discourse of empowerment divorces feminism from any type of coalitional politics and locates the source of women's power in their ability to labor for individual capital accumulation and ephemeral happiness. 


\section{Conclusion}

The hustling and female entrepreneurship products sold on Etsy romanticize working for yourself and the independence it offers. What these products don't speak to is the enhanced precarity of working without formal labor protections, health care, or steady wages. The Great Recession pushed unemployment and underemployment to historic highs; the economic impact of COVID-19 quickly blew past these numbers, and the effects have been especially devastating for women. Millions have had to rely on hustling in the absence of state support. While hustling, and its new, white appearance, is celebrated on Etsy, we must be mindful of how hustling is always raced, gendered, and precarious.

\section{Figures}

\section{Figure 1}

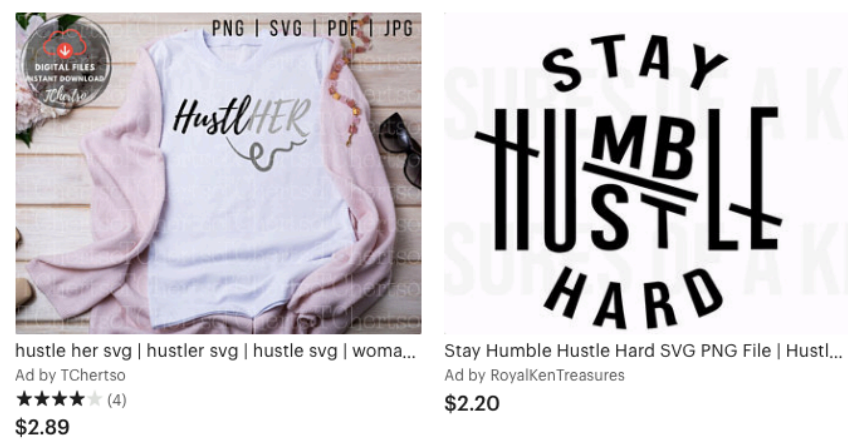

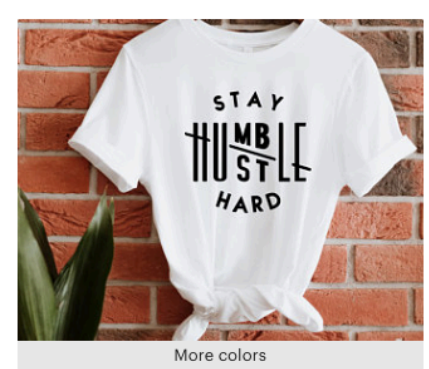

Stay Humble Hustle Hard T-shirt, Hustler T-shir. PreciousA

Figure 2

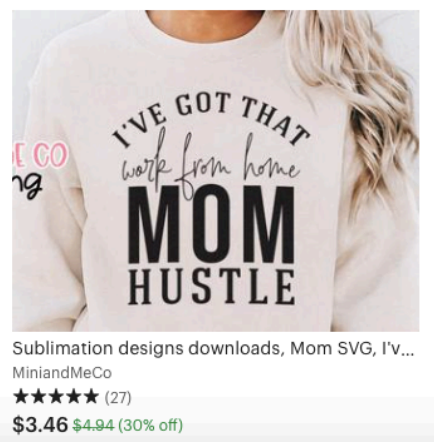



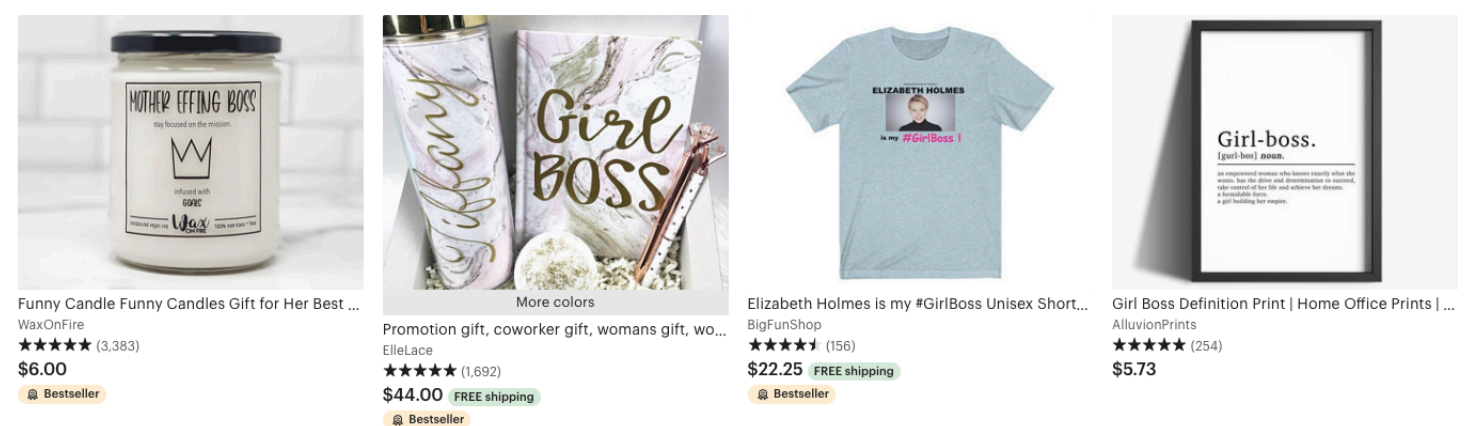

Girl Boss Definition
AlluvionPrints
$\star \star \star \star \star(254)$
$\$ 573$

$\$ 44.00$ FREE
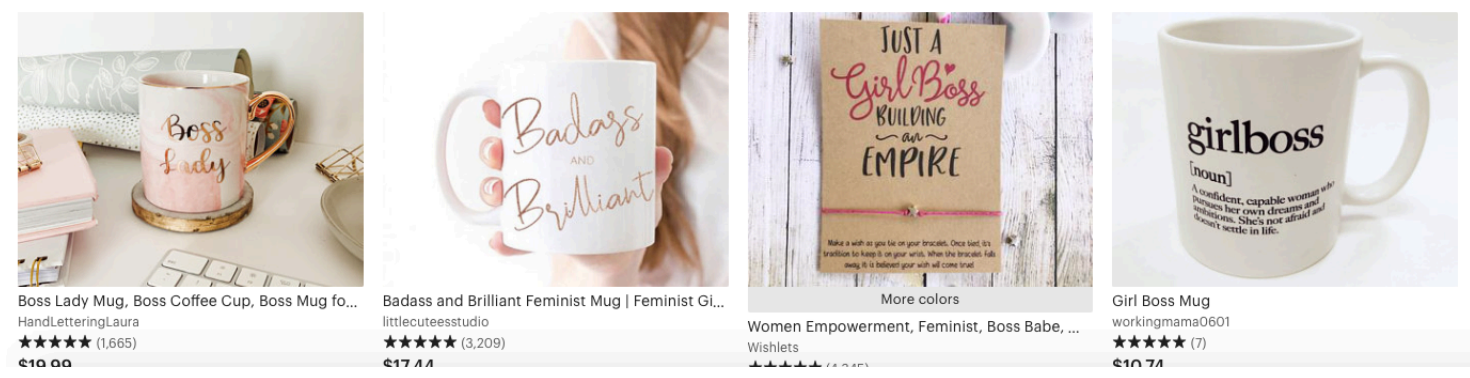

\section{References}

Brooke, E. (2018, September 18). Why bouncy, hyper-feminine script is the font of choice for bridesmaids gifts and novelty wine glasses. Vox.

https://www.vox.com/2018/9/18/17870200/script-bridesmaid-gifts-wine-glasses

Cherry, B. (2016). Cult media, fandom, and textiles: handicrafting as fan art. Bloomsbury Publishing.

Duffy, B. E. (2016). The romance of work: Gender and aspirational labour in the digital culture industries. International Journal of Cultural Studies, 19(4), 441-457. https://doi.org/10.1177/1367877915572186

Duffy, B. E. (2017). (Not) getting paid to do what you love: Gender, social media, and aspirational work. Yale University Press.

Gill, R. (2007). Postfeminist media culture: Elements of a sensibility. European Journal of Cultural Studies, 10(2), 147-166. https://doi.org/10.1177/1367549407075898

Krugh, M. (2014). Joy in labour: The politicization of craft from the arts and crafts movement to Etsy. Canadian Review of American Studies, 44(2), 281-301. https://doi.org/10.3138/CRAS.2014.S06

Luckman, S. (2013). The aura of the analogue in a digital age: Women's crafts, creative markets and home-based labour after Etsy. Cultural Studies Review, 19(1), 249-70. https://doi.org/10.5130/csr.v19i1.2585 
McMillan Cottom, T. (2020). The hustle economy. Dissent, 67(4), 19-25.

https://doi.org/10.1353/dss.2020.0094

McRobbie, A. (2004). Post-feminism and popular culture. Feminist Media Studies, 4(3), 255-264. https://doi.org/10.1080/1468077042000309937

McRobbie, A. (2018). Be creative: Making a living in the new culture industries. John Wiley \& Sons.

Negra, D., \& Tasker, Y. (Eds.). (2014). Gendering the recession: Media and culture in an age of austerity. Duke University Press.

Strine, A., \& Shoup, K. (2011). Starting an Etsy business for dummies. John Wiley \& Sons. 